ЭМОЦИИ И КОММУНИКАЦИИ В КУЛЬТУРНОМ ИЗМЕРЕНИИ

УДК 39

DOI: $10.33876 / 2311-0546 / 2022-3 / 7-19$

(C) Н.С. Розов

\title{
СОЦИАЛЬНО-АНТРОПОЛОГИЧЕСКИЙ ПОВОРОТ В ИССЛЕДОВАНИЯХ ГЛОТТОГЕНЕЗА: КОММУНИКАТИВНЫЕ ЗАБОТЫ И СТУПЕНИ ЯЗЫКОВОЙ СЛОЖНОСТИ
}

В статье структурированы и обобщень накопленные в мировой науке результаты исследований прочсхождения языка в связи с произошедшим сдвигом интереса: изучение орудийных технологий, костных останков и геномов гоминид дополняется реконструкцией их сочииальных взаимодействий и коммуникативных практик на основе разнообразных косвенных данных. Поставлены перспективные цели дальнейших исследований и намечень исходные идеи: 1) эскиз охватывающей понятийной конструкции с базовыми понятиями «социальные ниии», «коммуникативные заботы», «вызовыугрозы», «вызовы-возможности», «ответные стратегии», «обеспечивающие структуры», «ингредиентыл», «пробыл», «механизмы фиксации», «ступени языковой сложности», «глотто-ароморфозы»; 2) преодоление «языкового Рубикона» между коммуникативной системой животных и первой ступенью членораздельной речи; 3) ступени языковой сложности от различения слогов в коллективных сигналах (не)одобрения через протослова, реактивные и уводящие протофразы и протоязык типа пиджина - языку со сложными синтаксисом и грамматикой.

Ключевые слова: глоттогенез, происхождение языка, антропогенез, когнитивная эволючия, многоуровневый отбор, протоязык, культурный драйв, праязыки, коммуникации, социальный порядок, языковая сложность

Ссылка при цитировании: Розов Н.С. Социально-антропологический поворот в исследованиях глоттогенеза: коммуникативные заботы и ступени языковой сложности // Вестник антропологии, 2022. № 1. С. 7-19.

DOI: $10.33876 / 2311-0546 / 2022-3 / 7-19$

(C) N.S. Rozov

\section{A SOCIO-ANTHROPOLOGICAL TURN IN THE STUDIES OF GLOTTOGENESIS: COMMUNICATIVE CONCERNS AND LANGUAGE COMPLEXITY LEVELS}

The studies of the language origin have accumulated a substantial volume of ideas and results. Recently, the main interest of these studies has shifted from hominids'

Розов Николай Сергеевич - д.философ. н., профессор, главный научный сотрудник, Институт философии и права СО РАН (630090 Новосибирск, ул. Николаева, 8), зав. кафедрой социальной философии и политологии, Философский факультет НГУ. Эл. почта: nrozov@gmail.com 
tool technologies, bone remains, and genomes to the reconstruction of their social interactions and communication practices based on indirect evidence. The article sets the future goals for prospective research and outlines the basic ideas:

A sketch of an encompassing conceptual structure with the basic concepts of «social niches», «communicative concerns», "challenges-threats», «challenges-opportunities», «response strategies», "providing structures», «ingredients», «endeavors», "fixation mechanisms», «stages of linguistic complexity», "glotto-aromorphoses»;

Overcoming «the language Rubicon» between the communicative system of animals and the first stage of articulate human speech;

The steps of linguistic complexity from distinguishing syllables in collective signals of (dis) approval through proto-words, reactive and diverting proto-phrases, and a pidgin-like proto-language - to a language with complex syntax and grammar.

Keywords: glottogenesis, the origin of language, anthropogenesis, cognitive evolution, multilevel selection, proto-language, cultural drive, communication, social order, language complexity

For Citation: Rozov, N.S. 2022. A Socio-Anthropological Turn in the Studies of Glottogenesis: Communicative Concerns and Language Complexity Levels. Herald of Anthropology (Vestnik Antropologii) 1: 7-19.

Author Info: Rozov, Nikolai S. - Dr. Sc., Professor of Philosophy, Chief Researcher, the Institute for Philosophy and Law, Siberian Branch of Russian Academy of Sciences (Novosibirsk, Russia), Head of Department for Social Philosophy and Political Sciences, Novosibirsk State University. E-mail: nrozov@gmail.com

На пути к интегральной парадигме происхождения языка и сознания при всем разнообразии и широте идеи и подходов в последние годы вырисовывается некая общность. В исследованиях и в результатах наблюдаются следующие взаимосвязанные тенденции:

а) увеличение числа предположительных ступеней (стадий, этапов) эволюции языка;

б) удревнение ранних этапов вплоть до эпох гейдельбергцев, хабилисов и даже австралопитеков $(0,5,1,6$ или 4-6 млн лет назад);

в) более внимательный учет тесной связи языка с другими когнитивными способностями и сферами (сознание, память, культура, мышление, поисковая и конструктивная деятельность);

г) все более широкое признание значимости социальных взаимодействий, отношений, порядков (Бикертон 2012; Bouchard 2013; Барулин 2012; Dor et al 2014; Zlatev 2014; Sterelny 2016; Laland 2017; Tomasello 2019; Бурлак 2019; Markov, Markov 2020).

Уже можно говорить о складывающейся парадигме, объединяющей многие современные концепции глоттогенеза с чертами многоступенчатости, интегративности и социальности. Дальнейшие рассуждения и построения будем проводить на основе тех же принципов, но не ограничиваясь ими.

Поскольку прямых данных о процессах происхождения языка и сознания нет, все больше усилий направлено на сбор и осмысление косвенных данных - о коммуникации животных, о костных останках и артефактах гоминид, о генах и мозговых структурах, связанных с речью. Специалисты - авторы обширных и вдумчивых 
обзоров - делают неутешительные выводы об информативности этих результатов (Fitch 2009: 133; Wood, Bauernfeind 2012: 271). Выявлен т. н. «ген речи» FOXP2, свойства которого, характерные для человека, были обнаружены не только у ранних сапиенсов и протосапиенсов, но также у неандертальцев гейдельбергцев (Dediu, Levinson 2018; Бурлак 2019). А вот какие речевые задатки он мог обеспечивать, так и остается неизвестным (Dor, Knight, Lewis 2014: 56-66).

Следующие положения, получившие убедительные теоретические и/или эмпирические обоснования, здесь принимаются как исходные и не обсуждаются. Аргументация содержится в работах по ссылкам.

1. Речевое, или вербальное, общение, появилось как приспособление (adanmaция, обеспечивающая структура) в ходе антропогенеза как биологической, а затем социальной и культурной эволюции ${ }^{1}$ :

1) в процессах внутригруппового и межгруппового взаимодействия, коммуникации при действии механизмов многоуровневого отбора (Ламсден, Уилсон 2017; Deacon 1997; Jackendoff 2002; Пинкер 2004: 346; Barnard 2009; Dor et al 2014: 2; Laland 2017 и др.);

2) при обнаружении и построении новых техноприродных и сочиальных ниш (Odling-Smee, Laland, Feldman 2003; Бикертон 2012).

2. На начальных стадиях речевые способности уже у ранних Ното и архантропов развивались через положительные обратные связи с морфологическими изменениями гортани, увеличением мозга, особенно лобных (волевых) и височных (речевых) зон, нервными и мышечными механизмами контроля дыхания и т д. (Deacon 1997; Зубов 2004: 156-157; Барулин 2007; Wood, Bauernfeind 2012; Дробышевский 2017: 103-121). В последние два десятилетия разные исследователи на основе археологических данных получили важные датировки анатомических изменений гоминид, связанные с развитием речевой способности. Будем учитывать следующую сводку (со всеми оговорками приблизительности и разночтений датировок):

1) с 1,6 млн лет назад до 100 тыс. лет назад (далее - тлн) шло устойчивое развитие позвоночного столба (в частности, грудных позвонков), что позволяло контролировать дыхание;

2) между 400 и 300 тлн происходили изменения черепа, указывающие на опускание гортани (что считается необходимым условием способности к членораздельной речи - Н.Р.);

3) ок. 300 тлн подъязычные каналы увеличились до размеров, характерных для современного человека, что указывает на возможность контроля мелкой моторики;

4) специфические сапиентные изменения в «гене речи» FOXP2 появились ок. 300-200 тлн;

5) в останках протосапиенсов или ранних сапиенсов, датируемых ок. 100 тлн, строение подъязычных костей идентично человеческим.

\footnotetext{
1 Этот принимаемый тезис прямо противоречит сальтационной концепции ранних публикаций Н. Хомского и Д. Бикертона о позднем появлении языка или «узкой языковой способности» (к синтаксису, рекурсии) вследствие некой разовой мутации. Поэтому данная теория здесь не будет обсуждаться даже в ее смягченной версии (Hauser, Chomsky, Fitch 2002).
} 
3. Формирование совместной интенциональности и становление базовых социальных норм, вынужденные регулярные совместные действия и взаимопомощь стали необходимыми условиями развития речи (Выготский 2005; Томаселло 2011; Zlatev 2014; Tomasello 2019).

4. Вероятными структурами пресечения, предотвращения междоусобного насилия и агрессивного эгоистического поведения стали:

1) практика солидарного насилия в отношении нарушителей, последующих дружных групповых угроз (Bingham 2010),

2) эгалитарныле (в том числе женские) коалиции, разными способами сопротивлявшиеся мужской агрессии, приучавшие к дележу добычи, числе подвергавшие насильников, драчунов остракизму, что приводило к самоодомамниванию (Беляев 1981; Hrdy 1999; Lovejoy 2009; Power 2014; White et al. 2015; Wrangham 2019).

5. В микроситуациях «здесь и сейчас» говорение и слушание, т. е. использование речи обычно сопровождается особыми процессами эмоционально насыщенного взаимодействия и, вероятно, развитие речи, языка было глубинным образом связано с ними:

1) эмоциональная напряженность изначальной речевой коммуникации при трудностях понимания, с повторами, использованием мимики и жестикуляции, при сходстве с ритуалами (Deacon 1997; Laland 2017; Tomasello 2019);

2) систематическое исправление ошибок друг друга, совместное сосредоточение внимания, синхронизация ритмов, эмоиий, одновременные действия (Collins 2004; Бурлак 2019: 202).

Несмотря на солидные результаты исследований и достигнутый уровень согласия в принципиальных моментах (см. пп. 1-5) формирующаяся парадигма далека от завершения. Скорее, она представляет собой некий плацдарм для очередного продвижения в познании когнитивной эволюции вообще и происхождения языка, в частности. Перспективные исследовательские цели прямо связаны с главными трудностями и недостатками парадигмы:

- отсутствием обобщающего понятийного каркаса,

- $\quad$ крайней разнородностью методов и направлений как в дисциплинарном, так и в методологическом, интерпретационном аспектах, при слабом взаимном соотнесении или полном отсутствии такового.

\section{Коэволюция коммуникативных забот и языковых структур - эскиз охватывающего понятийного каркаса}

Концептуальная рамка для построения и проверки гипотез о разных аспектах и этапах глоттогенеза должна быть весьма широкой, способной охватить эволюционные процессы биологического (мозг, гортань, контроль дыхания), социального (взаимодействия, коммуникация), когнитивного (внимание, сознание, память, смыслы), поведенческого (речевые действия) и лингвистического характера (знаки, значения, языковые конструкции). Построение требуемого понятийного каркаса - большая самостоятельная теоретическая работа, поэтому здесь только намечу исходные идеи возможной версии, опирающейся на вышеизложенные принципы и идеи (пп. 1-5). Представленная ниже конструкция появилась под впечатлением, прежде всего, смелого сравнения Ч. Дарвиным эволюции видов и эволюции языков (Дарвин 2016: 407-408). 
Речь и язык появились как структуры для обеспечения менявшихся на протяжении антропогенеза потребностей общения, или коммуникативных забот. Новые заботы появлялись при вхождении в новые техноприродные ниши (взаимодействия с природной средой, менявшиеся в связи с развитием способов и технологий жизнеобеспечения) и социальнье ниши (порядки взаимодействия между индивидами в семьях, группах, а также между семьями и группами).

Новые ниши обычно проявляются как вblзовы-угрозы и вызовы-возможности для базовых потребностей индивидов, семей, групп в сферах безопасности, пропитания, сексуальности, родительства, статуса среди себе подобных. Ответные стратегии помимо материальных практик включают также социальные взаимодействия, предполагающие общение с потребностями передавать психологические состояния, смыслы (тревоги, желания, чувства, позже - мысли), а также убеждать, советоваться, мобилизовать на коллективные действия. Таким образом, специфика ниш, вызовов и стратегий формирует особенности типовых, повторяющихся потребностей - коммуникативных забот.

Среди обеспечивающих структур выделяются особенные, которые метафорически назовем волшебными палочками, поскольку они обладают удивительным свойством высокой пластичности и многофункциональности, громадным потенциалом развития, для которого иногда не видно пределов. В человеческом организме такой структурой стал мозг. В преистории и истории развертывались такие крупнейшие волшебные палочки как: язык, сознание, технологии, межпоколенная трансляция, мышление, познание, искусство.

В каждом конкретном языке фонемный строй, лексика и способы словообразования, набор синтаксических и грамматических конструкций также являются волшебными палочками, позволяющими обеспечивать практически любые коммуникативные заботы данного языкового сообщества; при недостаточности средств выражения открытые к развитию структуры языка позволяют обогащать лексику, а иногда и синтаксис с грамматикой.

Языковые структуры складывались из ингредиентов, полученных на предыдущих ступенях глоттогенеза, через пробы - многократные переиначивания, повторы с целью достичь взаимопонимания, и через механизмы фиксащии. Последние на разных уровнях осуществлялись следующим образом:

- на уровне ультрамикро- (в ситуациях «здесь и сейчас») через положительныле подкрепления;

- $\quad$ на уровне микро- (индивидуальное развитие, онтогенез) через социальное обучение;

- на уровнях мезо- (группы, альянсы групп) и макро- (языковые сообщества, будущие этносы) через «горизонтальную» культурную диффузию и «вертикальную» межпоколенную транслящию.

Механизмы фиксации в процессах генно-культурной коэволюции и культурного драйва закрепляли не сами языковые структуры, а только генные, анатомические и психофизиологическое основы развивавшихся задатков к овладению любого языка.

Главная причинность изначально направлена от техноприродных ниш к социальным нишам и порядкам взаимодействия, к коммуникативным заботам, обеспечивающим их языковым, когнитивным структурам, формированию их механизмов. Со временем практическое и социальное поведение все в большей мере формирует социальные ниши (охватывающие порядки) и природно-технологические ниши. 


\section{Преодоление «языкового Рубикона» - условия прорыва к речи}

Многие социальные животные используют для общения разнообразные голосовые синкретичные сигналы со значениями разного типа опасности, угрозы и претензии на доминирование, заигрывания и дружелюбия, покровительства, подчиненности, приглашения к игре (Фитч 2013). В чем же состояли уникальные особенности образа жизни, социальных взаимодействий, отношений порядков гоминид, которые обусловили когнитивную эволюцию человеческого рода вообще, происхождение и развитие членораздельного и осмысленного языка, в частности (Hurford 1999: 178)?

Потенциильные ингредиенты первых окончательно спустившихся на землю гоминид включали сильные эмоциональные связи, подражательство, гибкое жестовое и звуковое общение, свободные умелые руки, большой мозг при одновременном проигрыше в скорости передвижения, мышечной силе и размере челюстей (в сравнении с основными нишевыми конкурентами). Новая природная ниша, полная опасностей и трудностей в добывании пропитания сформировала заботу обеспечения сплоченности и взаимной поддержки внутри каждой группы. Складывавшиеся в ответ структуры при опоре на вышеуказанные ингредиенты стали наиболее тесно связаны с орудийными технологиями, координацией действий, общением, усложняющимися знаковыми средствами и когнитивными способностями.

Главными обеспечивающими структурами в социальной сфере стали совместная интенциональность, эгалитарные коалищии, противостоящие агрессивным альфа-самцам, нормы, ограничивающие насилие. Благодаря развитию этих структур происходил процесс самоодомашнивания (Беляев 1981; Lovejoy, 2009; Bingham 2010; Tomasello 2019; Wrangam 2019). В результате возникали такие социальные ниши и коммуникативные заботы, которых у других видов не было (лишь частично в группах шимпанзе и особенно бонобо (Waal 1995).

Главным драйвером развития языка представляется усложнение вызовов и забот в социильной сфере, причем практики обмена сообщениями вырастали в наслоение ниш с новыми вызовами-угрозами и вызовами-возможностями. Базовые сферы и типы забот - безопасность, пропитание, престиж, сексуальность, родительство остались, но социальные условия, допустимые пути достижения соответствующих интересов, целей неуклонно затруднялись и усложнялись. Это и вынуждало гоминид к поиску новых ответов, причем в той же избранной «колее» координациии действий через общение.

Так, при отсутствии подавляющих силой альфа-самцов появились возобновляющиеся обсуждения, совместное обдумывание и принятие решений, необходимость убеждать, согласовывать предложения. Борьба за доминирование через устрашение насилием сменилась конкуренциией за лидерство и престиж через мобилизацию поддержки. Запрет на сексуальное насилие привел к росту значимости ухаживания и заигрывания, которые стали осуществляться также через звуковую коммуникацию (Миллер 2000; Бикертон 2012; Power 2014; Zlatev 2014).

Разумеется, неуклонный, хотя и неравномерный прогресс орудийной деятельности тесно связан с языковым развитием и шире - с когнитивной эволюцией (Бунак 1966; Козинцев 2013). Однако связь здесь не прямая, одношаговая, как будто бы план будущего орудия непременно предполагал символическую способность (восходящая к Марксу идея, излюбленная археологами). Согласно изложенный выше модели эта связь опосредованная - двушаговая. Изобретение нового орудия, новой 
технологии обработки камня или кости могло удержаться в поколениях и получать распространение только через социальное обучение. В этой особой нише возникали специфические коммуникативные заботы, связанные с необходимостью обозначения и запоминания множества свойств сырья, тонкостей технических процедур, признаков и деталей изделий. Поэтому вместе с технологиями развивались как специальные языковые средства, так и более общие способности внимания, памяти, сознания, обучения и обучаемости ${ }^{1}$.

\section{Глотто-ароморфозы - подъемы по ступеням языковой сложности}

В условия прорывов к каждой новой ступени языковой сложности входит освоение потенциальных ингредиентов будущих обеспечивающих структур. Основу этих ступеней предположительно составляет следующая последовательность структур (см. также: Donald 1998; Gabora, Smith 2018; Jackendoff 2002; Bybee 2002; Burling 2005; Dessalles 2007; Бикертон 2012; Hurford 2012; Бурлак 2019):

- выделенные из синкретичных сигналов (успешно используемых животными) слоги - первые протослова-холофразы;

- умножение слогов и протослов благодаря различению фонем; соединение протослов в хаотичные наборы, цепочки - протофразы;

- трансформация протослов в полноценные слова с автономными от сиюминутных ситуаций и связанными между собой значениями; закрепление устойчивых соединений односложных слов в разнообразные свертки (составные слова и устойчивые речевые обороты - фраземы);

- появление схем порядка слов и преобразование протофраз в пиджин-предложения, что составляет протоязык;

- складывание конструкций простого синтаксиса, что уже характеризует настоящий язык;

- формирование грамматики согласований и конструкций сложного синтаксиса; последующее дополнение языка полисемией, рекурсией, риторическими украшениями и т. п.

\section{Обновление социальных порядков и коммуникативных забот - главные драйверы глотто-ароморфозов}

Кардинальную роль сыграло уверенное освоение огня (ок. 400-350 тлн, Дробышевский 2017: 123), забота поддержания которого принудительно подняла на новый уровень вербальную координацию действий и существенно расширила сознание во времени и пространстве 2 Освоение огня также открыло нишу коллективного приготовления пищи, а главное - публичное пространство совместных трапез (Рэнгем 2012). Трапезы изначально имели ритуальный характер ${ }^{3}$ и стали особыми пло-

\footnotetext{
${ }^{1}$ См. остроумные эксперименты, в которых сравнивалась успешность изготовления олдувайских и ашельских орудий учеником при варьировании допустимого типа коммуникации между ним и учителем (Laland 2017: 201-207).

${ }^{2}$ Широту сознания индивида составляют сферы, на предметах которых индивид способен фокусировать внимание, рассуждать о них либо в общении с другими субъектами, либо (на поздних стадиях развития) во внутренней речи, в мышлении, самопроизвольно и в одиночестве.

${ }^{3}$ Отнюдь неслучайно ритуальность совместных трапез в семьях, компаниях друзей, при важных
} 
щадками для дистантного контроля выполнения норм - вербальных презентаций, жалоб, споров, развертывания и разрешения конфликтов, ритуалов остракизма и солидарности. На этой стадии, вероятно, появился протоязык со стандартными схемами порядка слов, что позволяло сообщать о прошлых и отделенных ситуациях, т. е. развивалось важное свойство языковой перемещаемости, росли широта и произвольность сознания (Donald 1998; Gabora, Smith 2018).

В условиях растущей плотности населения, вынужденных миграций и участившихся столкновений учащались межгрупповые контакты (вероятно, в Африке ок. 250-100 тлн при переходе от протосапиенсов к ранним сапиенсам). Наряду с конфликтами, стычками создавались альянсы в целях охраны и расширения территорий, обмена (Stringer 2012: 280). Тогда новым драйвером усложнения коммуникации и языка стали переговоры.

Действительно, межгрупповые альянсы охотников-собирателей всегда предполагают брачную политику, обмены типа дар-отдар, ритуальные трапезы (Джонсон, Эрл 2017). Все это может происходить только благодаря переговорам и ритуальным соглашениям. Многочисленные данные о дальних «миграциях орудий» на основе происхождения сырья (Дробышевский 2017: 144) свидетельствуют о том, что межгрупповые контакты были не только конфликтными (когда орудиями завладевали победители, что вело к отчуждению и изоляции), но и мирными (когда налаживались цепи обмена), а значит без переговоров нельзя было обойтись.

В переговорах о границах территорий, правилах, конфликтах, возмещении обид и проч. приходилось говорить отнюдь не о наглядных ситуациях «здесь и сейчас», а значит протоязык и протослова уже были не достаточны. Протослова обретали автономию от ситуаций и произвольность, превращались в полноценные слова. В ту эпоху стали складываться первые синтаксические и грамматические конструкиии, что и означает переход от протоязыка к настоящему языку - к появлению потребностей и способностей выражать, понимать, а значит и осознавать внеситуационные предмеmbl, отношения, свойства (Burling 2005; Dessalles 2007; Givón 2009; Hurford 1999).

Уже на уровне верхнего палеолита (50-15 тлн) с взлетом орудийной технологии малые группы и даже индивиды стали способны добывать пропитание, что сильно усложнило социальную структуру с введением отложенных обменов, разнородных обязательств, с активизацией переговоров, сплетен, борьбы за престиж, публичных самопрезентаций и т. н. «макиавеллевского интеллекта», (Markov, Markov 2020; Sterelny 2016). Эти новые коммуникативные заботы объясняют складывание более сложных синтаксиса и грамматики, возможно, рекурсивности, полисемии, риторических украшений и т. п. В тесной связи с этими процессами развиваются способности сознания к легкому переключению между контекстами, ментальными переходами в пространстве и времени, между частью и целым, предметом и признаком и т. д. (Donald 1998; Desalles 2007: 238-244; Gabora, Smith 2018).

Тайна происхождения языка и сознания в антропогенезе, связанная с отсутствием прямых следов этих процессов, остается одним из главных интеллектуальных вызовов современной науки. Социально-антропологический поворот в исследованиях способствует прояснению ключевых проблем глоттогенеза благодаря знанию закономерностей поведения, социальных взаимодействий и с опорой на косвенные данные, получаемые дисциплинами широкого спектра от палеоклиматологии и археологии до палеогнетики.

встречах, собраниях, переговорах повсеместно до сих пор сохраняется. 


\section{Благодарности}

Автор выражает благодарность за ценные замечания, рекомендации, полезные ссылки специалистам, ознакомившимся с начальными идеями и версиями статьи: А.Н. Барулину, С.А. Бурлак, Л.Б. Вишняцкому, А.Г. Козинцеву, А.В. Маркову, А.А. Фомину.

\section{Научная литература}

Барулин А.Н. К построению теории глоттогенеза // Лингвистическая компаративистика в культурном и историческом аспекте. Материалы V Международной научной конференции по сравнительно-историческому языкознанию (Москва, 31января - 2 февраля 2006 г.) / отв. ред. В. А. Кочергина. Москва: МГУ, 2007. С. 9-44.

Беляев Д. К. О некоторых факторах эволюции гоминид // Вопросы философии, 1981. № 8. C. 69-77.

Бикертон Д. Язык Адама: как люди создали язык, как язык создал людей. Москва: Языки славянской культуры, 2012. 336 с.

Бунак В. В. Речь и интеллект, стадии их развития в антропогенезе // Ископаемые гоминиды и происхождение человека (Текст). / отв. ред. В. В. Бунак. Москва: Наука, 1966. С. 497-555.

Бурлак С. А. Происхождение языка. Факты, исследования, гипотезы. Москва: Альпина Диджитал, 2019. 292 с.

Выготский Л. С. Психология развития человека. Москва: Смысл; Эксмо, 2005. 1136 с.

Дарвин Ч. Происхождение видов. Москва: Эксмо, 2016. 480 с.

Дробышевский С. В.Антропогенез. Москва: Архэ, Модерн-А, 2017. 167 с.

Козинцев А. Г. Зоосемиотика и глоттогенез // Антропологический форум, 2013. № 19. С. 326-359.

Ламсден Ч. Дж., Уилсон Э. Прометеев огонь. Размышления о происхождении разума. Москва: УРСС: ЛЕНЛАНД, 2017. 304 с.

Миллер Д. Соблазняющий разум. Как выбор сексуального партнера повлиял на эволюцию человеческой природы. Москва: Corpus (АCT), 2000. 750 с.

Пинкер С. Язык как инстинкт. Москва: Едиториал, УРСС, 2004. 456 с.

Рэнгем Р. Зажечь огонь. Как кулинария сделала нас людьми. Москва: Астрель: CORPUS, 2012. $336 \mathrm{c}$

Томаселло М. Истоки человеческого общения. Москва: Языки славянских культур, 2011. 328 с.

Фитч У. Т. Эволюция языка. Москва: Языки славянских культур, 2013. 768 с.

Barnard A. Social origins: sharing, exchange, kinship // Botha, R., Chr. Knight (ed.). The Cradle of Language. Oxford Univ. Press, 2009: 219-235.

Bernabeu P., Vogt P. Language evolution: Current status and future directions // 10th LangUE Conference, Essex, UK, 2015: 1-27.

Bingham P. On the evolution of language: implications of a new and general theory of human origins, properties, and history // Larson, R. K., Déprez, V., Yamakido H. (ed.). The Evolution of Human Language:Biolinguistic Perspectives. Cambridge Univ. Press, 2010: 211-224.

Bouchard D. The Nature and Origin of Language. Oxford Univ. Press, 2013. 385 p.

Burling R. The Talking Ape. How Language Evolved. Oxford Univ. Press, 2005. 286 p.

Bybee J. Sequentiality as the basis of constituent structure // Givón T., Malle B. F. (ed.). The evolution of Language out of Pre-Language. Amsterdam; Philadelphia: John Benjamins, 2002: 109-134.

Collins R. Interaction Rituals Chains. Princeton Univ. Press, 2004. 439 p.

Deacon T. W. The Symbolic Species: The Coevolution of Language and the Brain. New York, NY: Norton, 1997. $527 \mathrm{p}$.

Dediu D., Levinson, S. C. Neanderthal language revisited: not only us // Current Opinion Behavioral Science, 2018, 21: 49-55.

Dessalles J.-L. Why We Talk. The Evolutionary Origins of Language. Oxford Univ. Press, 2007. 384 p.

Donald M. Hominid enculturation and cognitive evolution // Renfrew C., Scarre C. (ed.). Cognition 
and material culture: The archaeology of symbolic storage. Cambridge: McDonald Institute, 1998: 7-17.

Dor D., Jablonka E. Why we need to move from gene-culture co-evolution to culturally driven co-evolution // Dor D., Knight Chr., Lewis J. (ed.). The Social Origins of Language. Oxford Univ. Press, 2014: 15-30.

Dor D., Knight Chr., Lewis J. (ed.). The Social Origins of Language. Oxford Univ. Press, 2014. $308 \mathrm{p}$.

Dunbar R. I. M. Gossip in Evolutionary Perspective. Review of General Psychology, 2004, 8 (2): $100-110$.

Falk D. Prelinguistic evolution in early hominins: Whence motherese? // Behavioral and Brain Sciences, 2004, 27: 491-541.

Fitch W. T. Fossil cues to the evolution of speech. Botha R., Knight Chr. (ed.). The Cradle of Language. Oxford Univ. Press, 2009: 112-134.

Gabora L., Smith C.M. Two Cognitive Transitions Underlying the Capacity for Cultural Evolution. Journal of Anthropological Sciences, 2018, 96: 1-26.

Gärdenfors P., Osvath M. Prospection as a cognitive precursor to symbolic communication. Larson R. K., Déprez V., Yamakido H. (ed.). The Evolution of Human Language: Biolinguistic Perspectives. Cambridge Univ. Press, 2010: 103-114.

Givón T. The Genesis of Syntactic Complexity: Diachrony, Ontogeny, Neuro-Cognition, Evolution. Amsterdam; Philadelphia: John Benjamins Publ. Co., 2009. 366 p.

Hauser M.D., Chomsky, N., Fitch, W. T. The Faculty of Language: What Is It, Who Has It, and How Did It Evolve? // Science, 2002, 298(5598): 1569-1579.

Henrich J. The Secret of Our Success. How Culture Is Driving Human Evolution, Domesticating Our Species, and Making Us. Princeton University Press, 2016. 445 p.

Heyes C. M. What can imitation do for cooperation? // Calcott B., Joyce R., Sterelny K. (ed.). Signalling, commitment and cooperation. Cambridge, MA: MIT Press, 2012: 313-331.

Hrdy S. B. Mother Nature: A History of Mothers, Infants and Natural Selection. Boston: Pantheon Books, 1999. $752 \mathrm{p}$.

Hurford J. R. The evolution of language and of languages // Dunbar R., Knight C., Power C. (ed.). The Evolution of Culture. Edinburgh Univ. Press, 1999: 173-193.

Jackendoff R. Foundations of language: Brain, meaning, grammar, evolution. Oxford Univ. Press, 2002. $447 \mathrm{p}$.

Laland K. N. Darwin's unfinished symphony. How culture made the human mind. Princeton Univ. Press, 2017. $450 \mathrm{p}$.

Lloyd E.A. Kanzi, evolution, and language // Biology and Philosophy, 2004, 19: 577-588.

Lovejoy C.O. Reexamining Human Origins in Light of Ardipithecus ramidus // Science, 2009, 326 (5949): 74-74e8.

Markov A.V., Markov M.A. Runaway brain-culture coevolution as a reason for larger brains: Exploring the "cultural drive" hypothesis by computer modeling // Ecology and evolution, 2020, 10 (12): 1-19.

Nolfi S., Mirolli M. (ed.) Evolution of Communication and Language in Embodied Agents. Heidelberg, Dordrecht, London, New York: Springer 2010. 313 p.

Odling-Smee F. J., Laland K. N., Feldman M. W. Niche Construction: The Neglected Process in Evolution. Princeton Univ. Press, 2003. 468 p.

Power C. The Evolution of Ritual as a Process of Sexual Selection // Dor D., Knight Chr., Lewis J. (ed.). The Social Origins of Language. Oxford Univ. Press, 2014: 196-207.

Sterelny K. Cumulative Cultural Evolution and the Origins of Language // Biological Theory, 2016, 25: $173-186$.

Stringer Chr. Lone survivors: how we came to be the only humans on earth. Times Books, 2012.

Tomasello M. Becoming Human. A Theory of Ontogeny. The Belknap Press of Harvard Univ. Press, 2019, 379 p. 
Waal de F. B. M. Bonobo Sex and Society. The behavior of a close relative challenges assumptions about male supremacy in human evolution// Scientific American, March, 1995: 82-88.

White T. D., Lovejoy C. O., Asfaw B., Carlson J. P., Suwa G. Neither chimpanzee nor human, Ardipithecus reveals the surprising ancestry of both // PNAS, 2015, 112 (16): 4877-4884.

Wood B., Bauernfeind A. The fossil record: evidence for speech in early hominins // Tallerman M., Gibson K. (ed.). Language Evolution. Oxford Univ. Press, 2012: 258-272.

Wrangham R. The Goodness Paradox: The Strange Relationship Between Virtue and Violence in Human Evolution. Pantheon, 2019. 400 p.

Zlatev $J$. The co-evolution of human intersubjectivity, morality, and language // Dor D., Knight Chr., Lewis J. (ed.). The Social Origins of Language. Oxford Univ. Press, 2014: 249-266.

\section{References}

Barnard, A. 2009. Social origins: sharing, exchange, kinship. In The cradle of language, edited by R. Botha and Chr. Knight. Oxford Univ. Press: 219-235.

Barulin, A. N. 2007. K postroeniiu teorii glottogeneza [Towards the construction of the glottogenesis theory]. In Lingvisticheskaia komparativistika $v$ kul'turnom $i$ istoricheskom aspekte [Linguistic comparative studies in cultural and historical aspects], 9-44. Moscow: Moscow State Univ. Publ.

Belyaev, D. K. 1981. O nekotorykh faktorakh evoliutsii gominid [On Some Factors of Hominids' Evolution], Voprosy filosofii 8: 69-77.

Bernabeu, P. and P.Vogt. 2015.Language evolution: current status and future directions. In 10th LangUE Conference, 1-27. Essex, UK.

Bickerton, D. 2007. Adam's tongue. How humans made language, how language made humans. Hill and Wang.

Bingham, P. 2010. On the evolution of language: implications of a new and general theory of human origins, properties, and history. In The evolution of human language: biolinguistic perspectives, edited by R. K.Larson, V.Déprez, and H.Yamakido, 211-224. Cambridge Univ. Press.

Bouchard, D. 2013. The nature and origin of language. Oxford Univ. Press.

Bunak, V. V. 1966. Rech' i intellekt, stadii ikh razvitiia v antropogeneze [Speech and intellect, stages of their development in anthropogenesis]. In Iskopaemye gominidy i proiskhozhdenie cheloveka (Tekst) [Fossil hominids and the origin of man. Text], edited by V. V. Bunak, 497555. Moscow: Nauka.

Burlak, S. A. 2019. Proiskhozhdenie iazyka. Fakty, issledovaniia, gipotezy [The Origin of Language. Facts, Research, Hypotheses]. Moscow: Alpina Digital.

Burling, R. 2005. The talking ape. How language evolved. Oxford Univ. Press.

Bybee, J. 2002. Sequentiality as the basis of constituent structure. In The evolution of language out of pre-language, edited by T.Givón and B.F. Malle, 109-134. Amsterdam; Philadelphia: John Benjamins.

Collins, R. 2004. Interaction rituals chains. Princeton Univ. Press.

Darwin, Ch. (1859) 1958. On the origin of species. London: John Murray.

Deacon, T. W. 1997. The symbolic species: The coevolution of language and the brain. New York, NY: Norton.

Dediu, D. and S. C. Levinson, 2018. Neanderthal language revisited: not only us. Current Opinion Behavioral Science 21: 49-55.

Dessalles, J.-L. 2007. Why we talk. The evolutionary origins of language. Oxford Univ. Press.

Donald, M. 1998. Hominid enculturation and cognitive evolution. In cognition and material culture: The archaeology of symbolic storage, edited by Renfrew C. and C. Scarre, 7-17. Cambridge: McDonald Institute.

Dor, D. and E. Jablonka. 2014. Why we need to move from gene-culture co-evolution to culturally driven co-evolution. In The social origins of language, edited by Dor, D. Chr. Knight, and 
J. Lewis, 15-30. Oxford Univ. Press.

Dor, D. Chr. Knight, and J. Lewis. (ed.). 2014. The social origins of language. Oxford Univ. Press.

Drobyshevsky, S. V. 2017. Antropogenez [Anthropogenesis]. Moscow: Arhe, Modern-A.

Dunbar, R. I. 2004. Gossip in evolutionary perspective, Review of General Psychology 8 (2): 100-110.

Falk, D. 2004. Prelinguistic evolution in early hominins: Whence Motherese? Behavioral and Brain Sciences 27: 491-541.

Fitch, W. T. 2010. Evolution of language. Cambridge Univ. Press.

Fitch, W. T. 2009. Fossil cues to the evolution of speech. In: The Cradle of Language, edited by Botha R. and Chr. Knight, 112-134. Oxford Univ. Press.

Gabora, L. and C. M. Smith. 2018. Two cognitive transitions underlying the capacity for cultural evolution. Journal of Anthropological Sciences 96: 1-26.

Gärdenfors, P., and M. Osvath. 2010. Prospection as a cognitive precursor to symbolic communication. In: The evolution of human language: Biolinguistic Perspectives, edited by Larson R. K., V. Déprez, and H. Yamakido, 103-114. Cambridge Univ. Press.

Givón, T. 2009. The genesis of syntactic complexity: diachrony, ontogeny, neuro-cognition, evolution. Amsterdam; Philadelphia: John Benjamins Publ. Co.

Hauser, M.D., N. Chomsky, and W.T. Fitch, 2002. The faculty of language: what is it, who has it, and how did it evolve? Science 298 (5598): 1569-1579.

Henrich, J. 2016. The secret of our success. How culture is driving human evolution, domesticating our species, and making us. Princeton University Press.

Heyes, C. M. 2012. What can imitation do for cooperation? In: Signalling, commitment and cooperation, edited by Calcott, B., R. Joyce, and K. Sterelny, 313-331. Cambridge, MA: MIT Press.

Hrdy, S. B. 1999. Mother nature: a history of mothers, infants and natural selection. Boston: Pantheon Books.

Hurford, J. R. 1999. The evolution of language and of languages. In: The evolution of culture, edited by Dunbar, R., C. Knight, and C. Power, 173-193. Edinburgh Univ. Press.

Jackendoff, R. 2002. Foundations of language: brain, meaning, grammar, evolution. Oxford Univ. Press.

Kozintsev, A. G. 2013. Zoosemiotika i glottogenez [Zoosemiotics and Glottogenesis], Antropologicheskiy forum 19: 326-359.

Laland K. N. 2017. Darwin's unfinished symphony. How culture made the human mind. Princeton Univ. Press.

Lloyd, E.A. 2004. Kanzi, evolution, and language. Biology and philosophy 19: 577-588.

Lovejoy, C.O. 2009. Reexamining human origins in light of Ardipithecus ramidus. Science 326 (5949): 74-74e8.

Lumsden, E. O. and Ch. J. Wilson. 1983. Promethean fire: reflections on the origin of mind. Harvard Univ. Press.

Markov, A. V. and M. A. Markov. 2020. Runaway brain-culture coevolution as a reason for larger brains: Exploring the "cultural drive" hypothesis by computer modeling. Ecology and evolution 10 (12): 1-19.

Miller, G. 2001. The mating mind: how sexual choice shaped the evolution of human nature. Vintage.

Nolfi, S. and M. Mirolli. 2010. Evolution of communication and language in embodied agents. Heidelberg, Dordrecht, London, New York: Springer.

Odling-Smee, F. J., K. N. Laland, and M. W. Feldman. 2003. Niche construction: the neglected process in evolution. Princeton Univ. Press.

Pinker, S. 1994. The language instinct. New York, NY: Harper.

Power, C. 2014. The evolution of ritual as a process of sexual selection. In: The social origins of language, edited by Dor, D., Chr. Knight, and J. Lewis, 196-207. Oxford Univ. Press.

Sterelny, K. 2016. Cumulative cultural evolution and the origins of language. Biological theory, 25: $173-186$.

Stringer, Chr. 2012. Lone survivors: how we came to be the only humans on earth. Times Books.

Tomasello, M. 2008. Origins of human communication. Cambridge, MA: The MIT Press. 
Tomasello, M. 2019. Becoming human a theory of ontogeny. The Belknap Press of Harvard Univ. Press.

Vygotsky, L. S. 2005. Psikhologiia razvitiia cheloveka [The psychology of human development]. Moscow: Smysl Publ.; Eksmo Publ.

Waal de, F. B. M. 1995. Bonobo sex and society. The behavior of a close relative challenges assumptions about male supremacy in human evolution. Scientific American, March: 82-88.

White, T. D., C. O. Lovejoy, B. Asfaw, J. P. Carlson, and G. Suwa. 2015. Neither chimpanzee nor human, ardipithecus reveals the surprising ancestry of both. PNAS 112 (16): 4877-4884.

Wood, B. and A. Bauernfeind. 2012. The fossil record: evidence for speech in early hominins. In: Language Evolution, edited by Tallerman, M. and K. Gibson, 258-272. Oxford Univ. Press.

Wrangham, R. 2009. Catching fire. How cooking made us human. Profile books.

Wrangham R. 2019. The goodness paradox: the strange relationship between virtue and violence in human evolution. Pantheon.

Zlatev, J. 2014. The co-evolution of human intersubjectivity, morality, and language. In The social origins of language, edited by Dor, D., Chr. Knight, and J. Lewis, 249-266. Oxford Univ. Press. 